\title{
"USO ELEVADO DE LA MATEMATICA": EXIGENCIA DE INTELIGIBILIDAD FRENTE A FILOSOFIA EXPERINIENTAL
}

\author{
Victor Gómez Pin \\ (Universitat Autonoma de Barcelona)
}

\section{1. "Hypotesis non fingo": cuando la matemática reduce la filosofía a experimento}

En el espacio vacio (que en el plano ontológico Descartes como antes - aunque por razones diferentes - Aristóteles se negaba obstinadamente a admitir, pese a que su Geometria parece también tenerlo como postulado), los entes se situan relacionándose en conformidad a leyes que, cabe suponer, se hallaban prefiguradas en la mente del Creador. Ser reflejo humano de tales leyes, ser su archivador y consignador, se configura entonces como el destino del científico. Y asi, tras los pasos de Galileo y Kepler, surge el edificio de los Principia mahematica en los cuales parece cristalizar el sueño de /l Saggiatore.

Henry Moore habia atribuido al espacio caracteres propios de la divinidad misma: uno, simple, inmóvil, eterno, perfecto. Newton no llegará a este extremo, pero sí mantendrá entre el espacio y Dios un vinculo inextricable, que, en un aspecto fundamental, supondrá dependencia de la ciencia respecto de la teología y correlativo repudio de la exigencia explicativa, propia de la razón filosófica.

Pues entre las fórmulas descriptivas de los fenómenos celestes y terrestres tiene papel predominante aquella en la que se cuantifica la influencia que - por su mera existencia- dos cuerpos ejercen mutuamente; en el espacio vacio un cuerpo $A$ ejerce sobre un segundo $B$ una fuerza proporcional a la masa de ambos e inversamente proporcional al cuadrado de la distancia euclidiana entre ellos; distancia que puede eventualmente modificarse por el movimiento de los cuerpos, mas nunca en otro caso, tratándose del atributo euclidiano del espacio.

Mas ¿cuál es la causa de tal influencia? Aqui entra en juego la declaración de ignorancia que ha tenido quizás más influencia en la historia del pensamiento:

\begin{abstract}
No he logrado deducir de los fenómenos la razón de esta propiedad de la gravedad y no imagino hipótesis alguna [/ypolliesis non fingo]. Pues todo lo que no deriva de los fenómenos es una hipótesis $y$ las hipótesis (sean estas metalisicas, fisicas, mecénicas o que aventuran cualidades ocultas) no pueden ser admitidas en la fitosolia experimental. En la filosofia se extraen proposiciones de los fenómenos y después se las generaliza por inducción. Nos basta que la gravedad exista, que se manifieste en conformidad a las leyes que hemos expuesto y que se expliquen asl, tanto los movimientos de los cuerpos celestes como los del mar.
\end{abstract}

Basta con que la ley de la gravedad (nos dice Newton) explique los fenómenos de los cuerpos celestes y del mar. Pero ¿explica realmente? Describir no es explicar, dice un gran cientifico y filósofo contemporáneo del que más adelante nos ocuparemos.

¿"Basta con que las leyes..."? El tono del texto sugiere tanto lamentación como conformidad. Mas, en cualquier caso, la consecuencia es clara: filosofia... experimental, en lugar de filosofia a secas, filosofia que no se conformarí jamás con la mera constatación de lo dado.

Para los cartesianos, la acción a distancia suponia escándalo aun mayor que la vacuidad del marco en que tal acción transcurre. Y, de facto, cabe decir que aquella era una cunsecuencia de esta última. Verdadero insulto a la razón supone asimismo el asunto para Leibniz, tantas veces "enemigo" teorético de los cartesianos, quien acusa a Newton de proceder a una auténtica destrucción de la filosofia, buscadora por esencia de razones. Leibniz llega incluso a tildar 
de falsedad la pretensión de Newton de no aventurar hipótesis alguna. A su juicio la teoria está llena de hipótesis implicitas, simplemente se trataría de hipótesis poco meditadas (hipótesis "faineantes", llega a decir en los N'uevos Ensayos), fruto de alguna manera de una carencia de esfuerzo por parte de quien las formula.

$Y$ desde luego, hipótesis hay al menos una, vehiculada por la expresión misma ("Sensorum Dei") que caracteriza a espacio y tiempo como facultades de la percepción divina. Pues la manera de escapar al reproche cartesiano de que la acción a distancia supone irracional atribución a la materia de virtudes o cualidades ocultas, es considerar que Dios mismo es quien ejerce tal acción por mediación de su órgano espacial... Las förnulas describen los efectos de la voluntad, permanentemente actualizada, de Dios y, asi, la filosofia experimental, confundida con la ciencia positiva, encuentra apoyo último en la teología.

Apoyo ciertamente problemático, pues que Newton sólo explique la atracción univırsal recurriendo a la hipótesis del Creador resulta descorazonador hasta para los propios newtonianos... iTanta guerra con la Escoláslica tardía, para acabar afirmando que el estado mecánico inicial del sistema solar es una expresión de la voluntad divina!

No es pues de extrañar que los filósofos del siglo de las luces (aun admiticndo una especie de Dios ordenador, que actuaria como un relojero) tiendan a dejar de lado la hipótesis del sensorium Dei y a insistir en el aspecto más empirista de Newton, refiriéndose a la atracción como un mero dato de la experiencia.

Hernos señalado ya que tal empirismo resulta insatisfactorio para la razón. Pero quizás fuera preferible no remitir a causa alguna, que que hacerlo a una que es contraria a la erigercia de causas.

En fin, a este respecto las cosas se clarifican con Laplace, quien publica entre 1779 y 1825 su Tratado de mecónica celeste en cinco volümenes, presentando un mundo estrictamente determinado, en el que la teoría gravitatoria no exige ya recurso a la hipótesis de Dios, "hipótesis inútil" según Laplace. La ordenación de los planetas es un efecto de las leyes más generales del movimiento. Si se quiere a toda costa hacer intervenir la voluntad divina, ésta se situaria a la hora de determinar las leyes generales, y no las particulares de la atracción:

"Basth con que las leyes..." "Basta al matemático", decia Roberto Belarmino en ese otro texto mutilador de las esperanzas de la razón que antes hemos considerado. Basta al maternático Newton una matemítica, que en lugar de apuntar a la esencia de los fenómenos, se reduce a instrumento descriptivo de lo que se constata en los fenómenos.

Muchas veces se ha formulado la tesis de que la newtoniana filosofia experimental es una consecuencia directa de la matematización del universo, de la consideración privilegiada de las determinaciones cuantitativas en detrimento de las cualidades sensibles.

Pero cabe asimismo pensar que, en lugar de lastimosa concreción del proyecto pitagórico, la "filosofĩa experimental" es, más bien, una derivación asténica del mismo. De lo contra. rio, habría que incluir no sólo a Galileo o kepler en el repudio de la filosofia, sino remontarse a los platónicos tardios y (como hemos visto) quizás al propio Platón.

\section{La insatisfacción del newrtoniano E. Kant}

En la introducción a la Critica de la Razón Pura, Kant distingue, como es sabido, entre el conocimiento puro y aquel que consiste en meras generalizaciones de constataciones empiricas. A continuación afirma "cartesianamente" que ni siquiera el entendimiento común que caracteriza nuestras preocupaciones ordinarias podria darse si el espiritu no dispusiera de ciertos 
principios innatos; tras ello asigna como propedeútica de la filosolia una determinación de las condiciones de posibilidad y de la extensión de tales principios. Kant aborda entonces la cuestión clave de la diferencia entre atribuir un sujeto a un predicado que está implícitamente contenido en el (juicio analitico) o atribuirle un predicado que, de entrada no forma parte de sus determinaciones (juicio sintético).

Podriamos también denominar los primeros juicios explicativos y extensivos los segundos, ya que aquellos no añaden nada al concepto del sujero mediante el predicado, sino que simplemente lo descomponen en sus conceptos parciales, los cuales eran ya pensados en dicho concepto del sujeto (aunque de forma confusa). Por el contrario, los últimos aliaden al concepto del sujeto un predicado que no era pensado en él ni podia extraerse de ninguna descomposición suya. (Critica de la kazón Pura, Edición de Pedro Ribas, Alfaguara, p. 48)

Para hacernos más perceptible el problema, Kant, naturalnente, busca ejemplos. Si al lector se le pidiera encontrarlos por su cuenta, muy posiblemente diria cosas como: decir que Sócrates es un ser racional constituye un juicio analitico, dado que Sócrates es hombre, y que racional forma parte de la detinición de tal especie; por el contrario, atribuir al sonido la velocidad $\mathrm{x}$ constituye un juicio sintético, dado que ni siquiera en la concepción cientifica del sonido como una onda está implícito que se desplace a esa velocidad: la atribución sólo ha sido posible como resultado de esfuerzo, concretamente de mediciones empiricas, para llegar a ver lo que no estaba dado.

Pues bien, no serán estos los ejemplos ofrecidos por Kant ,sino otros cargados, por asi decirlo, de mayor mordiente. Citemos de nuevo el texto:

Si digo, por ejemplo: «todos los cuerpos son extensos», tenemos un juicio anstitico. En efecto, no tengo necesidad de ir más alla del concepto que ligo a ucuerpo" para encontrar la extensión como enla. zada con él. Para hallar ese predicado, no necesito sino descomponer dicho concepto, es decir, adquirir conciencia de la multiplicidad que siempre pienso en él. Se trata pues, de un juicio analitico. Por el contrario, si digo, «todos los cuerpos son pesados», el predicado constituy'e algo completamente distimto de lo que pienso en el simple concepto de cuerpo en general. Consiguientemente, de la adición de semejante predicado surge un juicio sintético (ibidem).

La consideración de la extensión como inherente a la corporeidad no produce sorpresa alguna, ni en el lector en general, ni en el formado por la lectura cartesiana: hablar de un cuerpo sin extensión aparece de inmediato como una contradicción. Que sea o no contradictoria la idea de una extensión sin corporeidad, es asunto más problemático. No hay contradicción, desde luego, para Newton (puesto que no otra cosa es el espacio en que Dios vino a ubicar las cosas) y tampoco para Kant. Si lo es, por el contrario, para Descartes, y no sólo por la negación del vacio que caracteriza a este autor. Por supuesto que sería ya absolutamete descabellada tratándose de Aristóteles, cuyo èter constitue la "quinta esencia", pero en modo alguno una realidad inmaterial. Pero pasemos al segundo ejemplo.

Si a un contemporáneo de Kant, algún precursor de los actuales pulsadores de opinión viniera a preguntarle si cabe algún cuerpo que no sea pesado, la respuesta seria, seguramente, que la cosa es tan absurda como sostener que hay cuerpos no extensos. Si el entrevistador añadiera la pregunta de porqué está tan seguro, el interlocutor diría posiblemente que, si la mano encierra un objeto, al abrirse aquélla éste cae. ¿Y si se trata de una pluma??, podria aun argüir el otro... en cuyo caso la respuesta empezaria a hacerse menos fäcil, y hasta imposible, si el entrevistado no fuera minimamente avisado en cuestiones de lilosotia galileana y newtoniana. 
Pues que la pluma no caiga, se "explica" por la ausencia de suficiente vacio, si partimos de la base de que la atracción de la materia ( $y$ ' en particular la atracción por la tierra de lo que se laalla en su entorno) es una ley de la naturaleza que no cabe discutir. Si se pregunta por qué no la lugar tal discusión, caben en principio las siguientes respuestas razonables: a) se trata de una evidencia fundadora; b) se trata de algo que se deduce de una evidencia fundadora; c) se trata de algo que hemos aceptado como premisa y no vamos ahora a desdecimos (ciertamente, esta respuesta implicaria que lo que se sustentara en tal principio careceria de todo peso ontológico). Pues bien:

Hemos visto que Newton no da al respecto ninguna de estus respuestas razonables. Newton dice que no avanza conjeturas porque... no cabe avanzar conjeturas, respecto a lo que la Providencia ha dispuesto. La atracción de la pluma por la tierra como manifestación de la fuerza gravitatoria, es algo que la filosofia experimental de Newton acepta, porque Dios asi lo ha ordenado.

Ahora bien: la Critica de la Razón Pura constituye un libro cuya finalidad es poner de relieve que, tratándose de conocimiento, la referencia a Dios es ilegítima. Tratándose de conocimiento, hay exigencias que la matemática y una fisica teórica digna de tal nombre (es decir, que enuncia juicios a la vez necesarios y no redundantes) si cumplen, pero que la filosofia experimental de Newton no cumple en modo alguno.

Para Kant, la matemática y la fisica no difieren en absoluto en cuanto al tipo de enunciados que efectuan: se trata, en ambos casos, de juicios sintéticos (es decir, no redundantes) y $a$ priori (es decir, auténticamente universales). la diferencia entre ambas disciplinas se sustenta tan sólo en un "pequeño" detalle: mientras que aquello (cuadrado, p, círculo, etc.) de lo que se ocupa el matemático no es un objeto empírico (y de facto sỏlo encuentra en la empiria imágenes deformadas), el fisico tiene conocimiento no empirico de algo que, de facto, se ubica en el ticmpo y el espacio. De ahi que la física sea una disciplina sintética a priori, no pura, rasgo este último que la separa de la matemática.

Por ello, cabe decir que la evocada elección de Kant a la hora de ilustrar en qué consiste un juicio sintético está cargada de connotaciones de insatisfacción, y hasta de repudio respecto a la disposición netvtoniana.

Tengo derecho a enunciar que el cuerpo $x$ es pesado, $y$ tal es el caso asimismo de y o de $z$. Pero no tengo derecho en modo alguno a enunciar "todo cuerpo es pesado", pues esta proposición es una generalización abusiva de meras constataciones empiricas; es una proposición sintética, pero no necesaria, lo contrario de las proposiciones de la matemática.

Sorprendido quedaría el "newtoniano Kant" si alguien le hubiera anunciado que algún dia la proposición "todo cuerpo es pesado" llegaria a ser legitima, pero ello en razón de que emergeria una física que pondria radicalmente en tela de jucio el otro presupuesto de su construcción, aquel en el que coincide con Newton; sorprendido quedaria Kant de llegar a barruntar que una teoria de la gravitación realmente explicativa, surgiria sobre las cenizas de las tesis del vacío como marco y de la primacia ontológica de la métrica euclidiana.

\section{Nostalgia de un uso filosófico de la matemática}

La canalización de la matemática hacia un uso meramente auxiliar de disciplinas empiricas trae irreversiblemente a la memoria los múltiples párrafos en los que Descartes se queja de tal res. tricción:

gustaba sobre todo de las matemáticas... pero no advertia cuál era su verdadero uso, y pensando que sólo para las artes mecánicas servian, extraisábame que, siendo sus cinientos tan firmes y sólidos, no se hubiese construido sobre ellos nada más elevado (Discurso del Mérodo, primera parte). 
Texto a completar con la siguiente alusión cargada de intencionalidad sobre los efectos perniciosos de la "pedagogia":

Deseariamos tener aqul un lector amante de la Aritmética y la Geometria, aunque seria preferible que no se hubiera aun ocupado de estas disciplinas a que lo hubiera hecho como se hace de ordinario... $Y$ no daré por supuesto nada de las maternáticas, salvo, eventualmente, ciertos axiomas conocidos por si misinos (per se nota) y al alcance de todo el mundo. Pues el conocimiento de tales disciplinas tal como se presentan de ordinairo aunque no halle alterado por error maniliesto, si se halla oscurecido por un gran número de principios desvirtuados o mal concebidos... (Reglas para la dirección del espirint: 442)

Descartes busca un lector deseoso del conocimiento matemático y que mantuviera no contaminado el substrato que motiva tal disposición. Nada menos fértil que una matenática tomada como fin en si, lo cual la asimilaria a un juego meramente formal; mas traición mayor, auténtica corrupción de los fines de inteligibilidad para los que la matemática es apta, es ponerla al servicio de meros objetivos de cómputo, descripción y previsión.

Un tercer texto citado por el historiador de la ciencia J.F. Manson es aun mayormente indicativo de la "nostalgia" cartesiana de una matemática con aspiraciones fïlosólicas:

Cuando recapacitaba cómo era que los primeros filósofos de épocas pretéritas se negaban a adınitir en el estudio de la sabiduria a quien no supiese matemáticas... vi confinnadas mis sospeclas de que tenian conocimiento de un tipo de matemáticas muy distinto del que es usual en nuestro tiempo.

En el tiempo de Descartes y en el nuestro cabria decir, aunque también ahora (como veremos) las actitudes de resistencia se dan. Tiempo de Descartes inarcado por Newton y no tanto por Galileo o Kepler, por la mecánica más bien que por la astronomía:

Pues cabe decir que en las formulaciones de Kepler la matemática conserva una suerte de dignidad ontologica. Se asigna a un planeta una órbita eliptica más bien que circular... ¿Resula esto de empirica constatación? ¿Resulta de evidenia "natural'"? Cientamente ni una cosa ni otra. Se trata de conjetura, sustentada en gran parte en la "pitagórica" confianza de que la naturaleza no toleraria un movimiento sin conformidad a figura geométrica alguna. "Pitagorismo" que se acentua aun en la hipótesis de que un cuerpo celeste sea intersección de los focos de las elipses trazadas por aquellos planetas que giran en torno a èl. La puerta de la intertogación filosófica, radicalmente metafisica, ests abienta: atales hechos constituyen atributos contingentes de la entidad del planets o más bien deteminaciones esenciales, de tal forma que el soporte material seria substrato de projección de la forma geométrica?

Por delirante que la segunda alternativa parezca a un pensamiento marcado por el "/ypothesis non fingo", atreverse a enunciarla es cuando menos signo de exigencia explicativa, de insatisfacción con el silencio de la razón que busca causas. De facto, a conjeturas no menos aventuradas se aferra Descartes cuando confrontado a la exigencia de buscar alternativa a la vacuidad y la acción a distancia nos habla de torbellinos:

“Descartes con sus torbellinos, explicaba todo y no calculaba nads... Newton con la ley de gravitación calculaba todo y no explicaba nada", escribe al respecto Rent Thom.

Y algo análogo cabria decir respecto a las determinaciones numéricas del movimiento. Decimos que un cuerpo se desplaza con movimiento uniforme (espacio $=c$ t, donde $\mathrm{c}$ es la constante velocidad) o bien uniformemente acelerado $\left(e=c t^{2}\right.$. donde $\mathrm{c}$ es la constante aceleración). Cabe suponer un movimiento más complejo (Así el expresado por la tercera ley de Kepler). Mas en cualquier caso se trataria aun de movimiento regido por una ley matemática. 
De lo que no nos ocupamos es de movimiento no sometido a malhema, movimiento arbitrario desde el punto de vista de la cifta. Ello ciertamente ni en el horizonte newtoniano ni en el kepleriano. Pero -insistimos - en el segundo caso la matemática parece aun un a priori de los fenómenos que ayuda a describir. Y ello ha de valer también para Galileo, a menos de tomar por pura retórica las líneas que prologan la célebre frase de / Saggiatore: "los caracteres [del libro de la filosofia] son triángulos, circulos y otras figuras geométricas sin mediación de las cuales es imposible la intelección de una sola palabra".

De hecho, si el respeto por la matemática no fuera en el caso de Galileo más alla del que se tiene por una herramienta sin vinculo con aquello a lo que se aplica ¿qué sentido tendria la sospecha de Roberto Belarmino de que Galileo - iy no sólo Copérnico!- estaba laciendo algo más que hablar ex suppositione.

De facto hay razones para pensar que Galilio habla aun menos ex suppositione que el propio Copérnico. Éste habia hecho del heliocentrismo una especie de postulado que eventualmente se revelaria útil para la explicación de algún fenómeno hasta entonces sorprendente.

Como hemos visto, Belarmino no hubiese objetado nada al respecto, salvo que de tal utilidad se pretendiera extraer la conclusión de que tal postulado era principio objetivo del orden natural; Belarmino en suma venia a decir: explica lo que quieras mientras aceptes que no estás haciendo otra cosa que explicar.

Supongamos pues que hay dos conjeturas opuestas (heliocentrismo y geocentrismo. por ejemplo) de las cuales una explica algo, mientras que la otra no lo hace y veamos lo que al respecto escribe Galileo:

\footnotetext{
Si se pudiera decir que ninguna de estas opiniones es verdadera, entonces podria afirmarse que una conviene mís que la otra a la hora de dar cuenta de las apariencias" ahora bien, dado que una de ellas ha de ser necesariamente falsa y la otra verdadera, mantener que sea la falsa la que mejor se adecủa a los efectos de la naturaleza es algo que realmente desborda mi imaginación. ("Consideraciones sobre la opinión copernicana" en Opuisculo sobre el movimiemo de la tierra, Alianza Editorial, 1983, p. 80)
}

Esta referencia al problema verdad-falsedad, la introduce Galileo y no el propio Copérnico. Retórica simple es, pues, la pretensión de Belarnino según la cual aun estima que sólo Copémico (y no también Galileo) otorga peso ontológico a la hipótesis del heliocentrismo.

\section{De Galileo a Descartes: revolución científica y problemática categorial}

De tener espacio evocariamos aqui a ese curiosisimo ancestro de Galileo y de Newton militante en las filas del ockamismo, en primer lugar como estudiante en Paris y más adelante como Maestro en el Colegio de Navarrra; evocariamos a Nicolàs de Oresme como ilustración del vínculo que cabria encontrar entre el distanciamiento respecto de una ontología que privilegia el papel de los universales y la apertura a una exploración fisico matemática del orden natural. Pues negar la objetividad de los universales supone negar su presencia en la Naluraleza (sea bajo forma platónica de participación o bajo forma aristotélica de inherencia) y con ello a excluir que en el conocimiento objetivo de la misma tengan la menor utilidad. Deslizarse entre éstos equivaldria como máximo a deslizarse en un horizonte de representaciones, forzosamente asténicas, de lo que propiamente son las cosas.

Lejos de que la "meseidad" se reproduzca en todas las mesas o la blancura en cada objeto blanco, hay un objeto-mesa singular y un segundo objeto semejante de los cuales, por abstracción de la existencia, surge en la mente esa ficción que representa (supponit) al individuo. En el 
mundo de las suposiciones se da una clase (la de los signos naturales, el humo respecto al fuego) que remite siempre a aquello que de por si significa, mientras que una segunda clase podria ser calificada de fantasmática dado que sólo remite a aquello que se conviene que signifique.

Estos universales convencionales son el universo de los predicables en los que de ordina. rio se complace la ciencia. Esta no consiste pues en reflejo en el pensamiento del universal presente en la cosa, sino en representación o erección del universal como consecuecia de fijarse en la semejanza y valorarla correlativamente al hecho de lacer abstracción de la cosa misma. Cabria decir que desde esta perspectiva la ciencia aristotélica consiste en el proceso de 1) repudiar la figura propia de lo individual, substancializando ese aspecto accidental que es la mera semejanza y 2) llegar a considerar que la primera es tan sólo resultado de materialización de la forma en la que consistiria la segunda.

Pero en tal caso queda abierta la via de una ciencia diferente, una ciencia tentada por las cosas reales. Apuntar a lo real de la cosa supone en primer lugar no dar importancia a la dimensión especifica que sabemos constituye un artificio, una representación con mayor o menor grado de arbitrariedad según que haya sido mas o menos forzada la constitución de semejanza. Mas el horizonte de las formas viene dado esencialmente por las cualidades. E! lastre de relatividad, subjetividad y variabilidad que, en la perspectiva nominalista, se atribuye a los universales marca asimismo las cualidades, marca como tal el orden de la determinación cualitativa. Nada extraiło, pues, en que la ciencia que se abre camino y que tendría en el nominalismo substrato ontológico, se traduzca esencialmente en una exploración de las posibilidades de la determinación cuantitativa. Nada extraño en que números y figuras (es decir, las dos modalidades en las que se da la determinación cuantitativa, según el capitulo consagrado a ésta en las categorias de Aristóteles, juequen a partir de entonces un papel preponderante.

Se reconoce usualmente a Galileo el título de filósofo que reivindicaba, en base ciertamente no a un inexistente sistema sino a las implicaciones filosóficas de su obra. Pues bien: cabe decir que las posiciones de Galileo remiten a una problematica no ya filosótica en un sentido indeterminado, sino directamente ontológica y hasta ontológico-categorial y ello exactamente en relación al problema que estamos evocando.

Pues no otra cosa que una auténtica revolución categorial suponen las critica realizadas por Galileo a las tesis ortodoxas de que los sensibilia propia (es decir aquellos que son percibidos a través de un sólo sentido) son fiables, mientras que no lo serian los sensibilia communia (susceptibles de ser percibidos a través de más de un sentido). Pues los primeros son aquellos atributos del objeto que pertenecen al registro cualitativo, mientras que los segundos son tradicionalınente adscritos al registro cuantitativo.

$Y$ asi la valoración de la percepción de dimensión, figura, tiempo, espacio y muvimiento frente a la valoración por ejemplo del color o el sabor, supone que, efectivamente, la hilosolĩa (según la lrase literal del Saggiatore $\% / a$ fllosofia está escrita...) tiene su elemento nuclear en la cuestión ontológico categorial y que a una revolución en este registro es a lo que (implícita o explicitamente) esta aludiendo // Saggiatore.

¿Estamos, como suele decirse, ante un doblete en el registro cientifico de esa restauración tantas veces intentanda en el terreno más especificamente filosólico? En parte desde luego, tanto más si consideramos un aspecto suplementario, a saber, que la conviceión del carácter matemálico del universo no resulta aún de una práclica de la exploración de tśste sino que -en el tiempo de Galileo- constiluye tan sólo un "a priori”. Restaunción en todo caso del platonismo sui generis de la Academia tardia (tan criticado por Aristóteles), cuya tentación pitagórica puede considerarse como una desconfianza en la fertilidad ontológica de la koria 
tradicional de las ideas, más bien que resultado de una imposible comprobación de la eficacia de las ideas-números. Para el platonismo ingenuo de los "amigos de las formas" y el platonismo ortodoxo de los diálogos centrales, la nueva ciencia supone la misma amenaza que para la filosofia aristotélica, que en la entidad privilegia el eidos como conjunto unificado de elementos archivables en la categoría de cualidad.

Apuntando a la Naturaleza marcada por movimiento, ligura, número, extensión... una etapa del racionalismo es clausurada por otra etapa del racionalismo; asunto en el que es necesario insistir dado lo ambiguo de la expresión "racionalismo cartesiano", usada en ocasiones como si ambos términos fueron sinónimos. Tan racionalistas son ciertamente las filosofias platónica, aristotélica o aristotélico-tomista como la que subyace en // Saggiatore y que efectivamente encontrará en Descartes su punto de concretización. El particular replanteamiento por Descartes de la cuestión que ocupaba a Galileo relativamente a la fiabilidad de los sentidos (Beltran: 1987: 3-30) conduce en las Meditaciones a ese momento clave en que (inmersos en la hipótesis del sueño $\mathrm{e}$ instrumentalizando la metálora del pintor), lo nuclear de la nueva ordenación se impone.

Señalan los biógrafos de Descartes que hallándose de regreso (en Abril de 1.625) de Holanda a Paris, habria tenido noticia de las últimas palabras pronunciadas por el Principe de Orange, Maurice de Nassau, al ser interrogado sobre si -ante la inminencia de la muertemantenía su fe: "creo que dos y dos son cuatro", habria sido la respuesta.

Tocamos aqui un problema clave. ¿Puede el escepticismo llegar a abarcar los principios de la matemática? Y aún: ¿es la hipótesis de Dios más frágil que la "hipótesis" de que dos y dos son cuatro? Maurice de Nassau habia sido, comandante de Descartes en su primera aventura militar. ¿Vendrá asimismo a ser simbólico guia en cuestiones onto-teológicas? (Todo depende de la lectura que se haga de los textos en los que se sustenta la metafisica cartesiana y en primer lugar de las Meditaciones de Prima filosofia. En términos estrictos de la problemática cartesiana la alternativa es clara: cabe estimar que la matemática (incluida entre aquellos casos que "generalmente son tomados por ciertos mas que han de ser objetos de duda") sólo puede ser salvada por la mediación de Dios; cabe por el contrario considerar que Dios es respecto a la matemática "una hipótesis inútil" (Laplace) e incluso que sólo puede ser aventurada como hipótesis si los principios en los que la matemática reposa son invulnerables. 